\title{
A NEW AIR CONDITIONING SYSTEM FAN MODEL BASED ON NUMERICAL ANALYSIS
}

\author{
Nabil Nassif, Raymond Tesiero and Nihal AlRaees \\ Department of Civil, Architectural and Environmental Engineering, \\ North Carolina A and T State University, NC 27411, Greensboro, USA
}

Received 2014-01-29; Revised 2014-02-21; Accepted 2014-03-14

\begin{abstract}
A large portion of energy use in buildings is attributed to air movement devices. Accurate estimation of fan performance is a key element in maximizing fan efficiency. This study proposes a new fan model that can be used in several applications such as optimization and fault detection and can also be incorporated into any commercial building models. The model uses a numerical analysis based on an interpolation technique for the data generated by basic fan laws. It can use any two variables among all four variables of airflow rate, total fan pressure, speed and power as inputs or outputs. Another advantage of this model is the flexibility of using any size of data for calibration, obtained either from manufacturers or field measured data. The model was tested for accuracy using two different manufacturers' data of roof top unit packages with capacity ranging from 2 to 20 tons. Furthermore, the model was evaluated and tested on an actual VAV system using three months' worth of measured data. The results show that the model can provide accurate estimation with the Coefficient of Variance (CV) less than $2 \%$ and it can be used for several applications.
\end{abstract}

Keywords: Fan Model, HVAC System, Modeling

\section{INTRODUCTION}

A large portion of energy use in buildings is attributed to energy use in air movement devices. Heating, cooling, ventilation and refrigeration in residential and commercial buildings consumed 8.2 quads of primary electric energy in 2006 and an estimated 2.4 quads are expended through the movement of indoor and ventilation makeup air in commercial and institutional buildings (EERE, 2010; Dieckmann et al., 2010). Accurate estimation of fan performance is a key element in reducing energy consumption associated with fan operations. In existing systems, optimization, intelligent control and fault detection and diagnostic need an accurate model to estimate either fan airflow rate and power or static pressure and power. Another application is the use of the modern airflow station technique (Joo et al., 2007). The fan model can determine the airflow by using the measured fan differential pressure and fan speed. The success of this technique is related to the model accuracy and the amount of data to be collected on site for calibration. In simulation software application, the designer has to use airflow and fan pressure as inputs to the fan model in order to calculate fan power.

There are several models proposed in literature (Nassif et al., 2008; Stein and Hydeman, 2004; Brandemuehl et al., 1993; Clark 1985; Nassif, 2008). Those models do not provide flexibility in selecting the input and output variables and have their limitations in many applications. The simple model in DOE-2 (DOE, 1980) and HVAC 2 toolkit (Brandemuehl et al., 1993) uses a third order regression model in order to estimate the power as a function of airflow rate. The detailed model in HVAC 2 toolkit (Brandemuehl et al., 1993), based on Clark's model (Clark, 1985), characterizes the fan performance in terms of pressure rise across the fan and shaft power. The detailed model does not permit the direct Corresponding Author: Nabil Nassif, Department of Civil, Architectural and Environmental Engineering,

North Carolina A and T State University, NC 27411, Greensboro, USA

Tel: (336) 285-3680 Fax: (336) 334-7126 
calculation of fan power from airflow and pressure. It requires both airflow and fan speed as inputs to correlate the efficiency to the dimensionless flow term.

This study proposes a new fan model that can be used in several applications and can also be incorporated into any commercial building models. The fan model uses numerical methods based on an interpolation technique from data generated by basic fan laws. It can be calibrated with two or more data points for better accuracy. Using the variables of airflow rate, total fan pressure, speed and power, the model is flexible in using any two of those variables as inputs or outputs. The model proposed in this study will overcome the aforementioned existing model limitations by selecting any input or output variables and any set of data for calibrations. To test the model, two different manufacturers' data of roof top unit packages with capacity ranging from 2 to 20 tons ( 7 to $70.2 \mathrm{~kW}$ ) are first used. Then the model is tested and evaluated on an actual Variable Air Volume (VAV) system using three months' worth of measured data.

\section{FAN MODELS}

\subsection{Model Description}

Many models have been proposed in literature. The Simple Fan Model (SFM) in DOE-2 and HVAC 2 toolkit (Brandemuehl et al., 1993 and DOE, 1980) uses a third order regression model to estimate the power Ws as a function of airflow rate $\mathrm{Q}$ as follows Equation 1:

$$
\frac{\mathrm{W}_{\mathrm{s}}}{\mathrm{W}_{\mathrm{rat}}}=\mathrm{C}_{0}+\mathrm{C}_{1} \frac{\mathrm{Q}}{\mathrm{Q}_{\mathrm{rat}}}+\mathrm{C}_{2}\left(\frac{\mathrm{Q}}{\mathrm{Q}_{\text {rat }}}\right)^{2}+\mathrm{C}_{3}\left(\frac{\mathrm{Q}}{\mathrm{Q}_{\text {rat }}}\right)^{3}
$$

The $\mathrm{W}_{\text {rat }}$ and $\mathrm{Q}_{\text {rat }}$ are the rated power and airflow rate. This model requires at least four different operating points to find the polynomial coefficients $\left(\mathrm{C}_{0}, \mathrm{C}_{1}, \mathrm{C}_{2}\right.$ and $\left.\mathrm{C}_{3}\right)$. Simulation software generally uses default values, or left options, as user inputs. The model is based on the assumption of a single system curve and constant pressure rise across the fan (Stein and Hydeman, 2004). However, in real applications such as VAV systems, the system curve varies with the relative changes in the damper positions of VAV boxes and the pressure rise is not constant due to various load and static pressure reset control algorithm.

The other model in HVAC toolkit is a Detailed Fan Model (DFM) (Brandemuehl et al., 1993; Clark, 1985). In this model, the fan performance is characterized in terms of pressure rise across the fan $(\Delta \mathrm{p})$ and shaft power $(\mathrm{W})$. It uses the dimensionless coefficients of flow $(\Phi)$, pressure head $(\psi)$ and shaft power $\left(\eta_{\mathrm{f}}\right)$, as follows Equation 2 to 4 :

$$
\begin{aligned}
& \Phi=\frac{\mathrm{Q}}{\mathrm{N} \cdot \mathrm{d}^{3}} \\
& \Psi=\frac{\Delta \mathrm{P}}{\rho \cdot \mathrm{N}^{2} \cdot \mathrm{d}^{2}} \\
& \eta_{\mathrm{f}}=\frac{\mathrm{Q} \cdot \Delta \mathrm{P}}{\mathrm{W}}
\end{aligned}
$$

where, $\mathrm{d}$ is the fan diameter, $\rho$ is the air density and $\mathrm{N}$ is the fan speed. The performance of a fan is represented by a fourth order polynomial regression of the manufacturer's data using these dimensionless coefficients Equation 5 and 6:

$$
\begin{aligned}
& \Psi=\mathrm{a}_{0}+\mathrm{a}_{1} \Phi+\mathrm{a}_{2} \Phi^{2}+\mathrm{a}_{3} \Phi^{3}+\mathrm{a}_{4} \Phi^{4} \\
& \eta_{\mathrm{f}}=\mathrm{b}_{0}+\mathrm{b}_{1} \Phi+\mathrm{b}_{2} \Phi^{2}+\mathrm{b}_{3} \Phi^{3}+\mathrm{b}_{4} \Phi^{4}
\end{aligned}
$$

The coefficients, $a_{i}$ and $b_{i}$ are determined from the manufacturer's data.

The main problem of this model is that the model assumes fixed peak efficiency for fans of all sizes (Stein and Hydeman, 2004). In addition, the model does not allow direct calculation of fan efficiency from airflow and pressure. It is required to use airflow and fan pressure as inputs to calculate fan speed and efficiency.

As a result of these shortcomings, a fan model is proposed in this study. The proposed model is based on numerical analysis and an interpolation technique for the data obtained by principle fan laws. This model will allow the user to select any two variables as inputs or outputs among all four variables of air flow $\mathrm{Q}$, total pressure $\mathrm{P}$, speed $\mathrm{N}$ and power $\mathrm{W}$. The model needs at least two different operating points for calibrations, obtained from manufacturers or measurements, referred to here as MD. The model output and the model inputs are referred to here as MO and MI, respectively. The procedure to find the model output MO is described below:

\section{Given:}

$\mathrm{MD}=[\mathrm{Q}, \mathrm{P}, \mathrm{N}, \mathrm{W}]=[$ Flow, Pressure, Speed, Power $]$ Inputs:

$\mathrm{MI}=\left[\mathrm{MI}_{1}, \mathrm{MI}_{2}\right]=[\mathrm{P}, \mathrm{N}],[\mathrm{Q}, \mathrm{P}],[\mathrm{Q}, \mathrm{N}],[\mathrm{P}, \mathrm{Q}]$, or etc.

Outputs:

$\mathrm{MO}=\left[\mathrm{MO}_{1}, \mathrm{MO}_{2}\right]=[\mathrm{Q}, \mathrm{W}],[\mathrm{N}, \mathrm{W}],[\mathrm{P}, \mathrm{W}],[\mathrm{W}, \mathrm{N}]$, or etc. 
To find the outputs, the Internal Variables (IV) are first generated from fan laws and using one variable of the input $\left(\mathrm{MI}_{1}\right)$ :

$$
\mathrm{IV}=\text { fan laws }\left(\mathrm{MD}, \mathrm{MI}_{1}\right)
$$

Second, the model outputs MO are then found from any interpolation/extrapolation techniques such as linear or polynomial interpolation:

$$
\mathrm{MO}=\text { interpolation / extrapolation }\left(\mathrm{IV}, \mathrm{MI}_{2}\right)
$$

Three examples below show the implementation of the aforementioned procedure.

\section{Example 1}

In this example, it is assumed that there are two operating points $\left(\mathrm{A}_{1}\right.$ and $\left.\mathrm{A}_{2}\right)$ obtained from the manufacturer's data or by performing on-site measurements. Those points are used for the model calibration and depicted in Fig. 1 that also shows typical fan characteristic performance curves. The operating points $\left(A_{1}\right.$ and $\left.A_{2}\right)$ contain the measured variables of flow rates $\left(\mathrm{Q}_{\mathrm{A} 1}\right.$ and $\left.\mathrm{Q}_{\mathrm{A} 2}\right)$, total static pressures $\left(\mathrm{P}_{\mathrm{A} 1}\right.$ and $\mathrm{P}_{\mathrm{A} 2}$ ), fan speed $\left(\mathrm{N}_{\mathrm{A} 1}\right.$ and $\left.\mathrm{N}_{\mathrm{A} 2}\right)$ and fan power $\left(\mathrm{W}_{\mathrm{A} 1}\right.$ and $\mathrm{W}_{\mathrm{A} 2}$ ). Thus, the objective is to find the airflow rate $\mathrm{Q}_{\mathrm{B} 0}$ and fan power $\mathrm{W}_{\mathrm{B} 0}$ (point $\mathrm{B}_{0}$ ) from the total fan pressure $\mathrm{P}_{\mathrm{B} 0}$ and speed $\mathrm{N}_{\mathrm{B} 0}$.

Available data for calibrations $\mathrm{A}_{1}$ and $\mathrm{A}_{2}$ :

$$
\mathrm{MD}=\left[\mathrm{Q}_{\mathrm{A} 1}, \mathrm{P}_{\mathrm{A} 1} \mathrm{~N}_{\mathrm{A} 1}, \mathrm{~W}_{\mathrm{A} 1}, \mathrm{Q}_{\mathrm{A} 2}, \mathrm{P}_{\mathrm{A} 2}, \mathrm{~N}_{\mathrm{A} 2}, \mathrm{~W}_{\mathrm{A} 2}\right]
$$

- Inputs: Total fan pressure $\mathrm{P}_{\mathrm{B} 0}$ and speed $\mathrm{N}_{\mathrm{B} 0}, \mathrm{MI}=$ $\left[\mathrm{P}_{\mathrm{B} 0}, \mathrm{~N}_{\mathrm{B} 0}\right]$

- Outputs: The airflow rate $\mathrm{Q}_{\mathrm{B} 0}$ and fan power $\mathrm{W}_{\mathrm{B} 0 \text {, }}$ $\mathrm{MO}=\left[\mathrm{Q}_{\mathrm{B} 0}, \mathrm{~W}_{\mathrm{B} 0}\right]$

- $\quad \mathrm{IV}=$ Internal variables generated from fan laws (B1 and $\mathrm{B} 2)$ using the input fan static pressure $\left(\mathrm{P}_{\mathrm{B} 0}\right)$ where $\left(\mathrm{P}_{\mathrm{B} 0}=\mathrm{P}_{\mathrm{B} 1}=\mathrm{P}_{\mathrm{B} 2}\right)$ Fig. 1 Equation 7 to 9 :

$$
\begin{aligned}
& \mathrm{Q}_{\mathrm{B} 1}=\mathrm{Q}_{\mathrm{A} 1}\left(\frac{\mathrm{P}_{\mathrm{B} 0}}{\mathrm{P}_{\mathrm{A} 1}}\right)^{0.5}, \mathrm{Q}_{\mathrm{B} 2}=\mathrm{Q}_{\mathrm{A} 2}\left(\frac{\mathrm{P}_{\mathrm{B} 0}}{\mathrm{P}_{\mathrm{A} 2}}\right)^{0.5} \\
& \mathrm{~W}_{\mathrm{B} 1}=\mathrm{W}_{\mathrm{A} 1}\left(\frac{\mathrm{P}_{\mathrm{B} 0}}{\mathrm{P}_{\mathrm{A} 1}}\right)^{1.5}, \mathrm{~W}_{\mathrm{B} 2}=\mathrm{W}_{\mathrm{A} 2}\left(\frac{\mathrm{P}_{\mathrm{B} 0}}{\mathrm{P}_{\mathrm{A} 2}}\right)^{1.5} \\
& \mathrm{~N}_{\mathrm{B} 1}=\mathrm{N}_{\mathrm{A} 1}\left(\frac{\mathrm{P}_{\mathrm{B} 0}}{\mathrm{P}_{\mathrm{A} 1}}\right)^{0.5}, \mathrm{~N}_{\mathrm{B} 2}=\mathrm{N}_{\mathrm{A} 2}\left(\frac{\mathrm{P}_{\mathrm{B} 0}}{\mathrm{P}_{\mathrm{A} 2}}\right)^{0.5}
\end{aligned}
$$

To find the variables of the point $\mathrm{B}_{0}$, an interpolation technique such as linear or polynomial interpolation is used. Both the linear and polynomial interpolation techniques were tested and the results were about the same. Thus, to simplify our discussions, only the linear technique is discussed. Thus, the model outputs $\left(\mathrm{B}_{0}\right)$ are Equation 10 and 11:

$$
\begin{aligned}
& \mathrm{Q}_{\mathrm{B} 0}=\frac{\mathrm{N}_{\mathrm{B} 2}-\mathrm{N}_{\mathrm{B} 0}}{\mathrm{~N}_{\mathrm{B} 2}-\mathrm{N}_{\mathrm{B} 1}} \times \mathrm{Q}_{\mathrm{B} 1}+\frac{\mathrm{N}_{\mathrm{B} 0}-\mathrm{N}_{\mathrm{B} 1}}{\mathrm{~N}_{\mathrm{B} 2}-\mathrm{N}_{\mathrm{B} 1}} \times \mathrm{Q}_{\mathrm{B} 2} \\
& \mathrm{~W}_{\mathrm{B} 0}=\frac{\mathrm{N}_{\mathrm{B} 2}-\mathrm{N}_{\mathrm{B} 0}}{\mathrm{~N}_{\mathrm{B} 2}-\mathrm{N}_{\mathrm{B} 1}} \times \mathrm{W}_{\mathrm{B} 1}+\frac{\mathrm{N}_{\mathrm{B} 0}-\mathrm{N}_{\mathrm{B} 1}}{\mathrm{~N}_{\mathrm{B} 2}-\mathrm{N}_{\mathrm{B} 1}} \times \mathrm{W}_{\mathrm{B} 2}
\end{aligned}
$$

\section{Example 2}

In this example, a set $\mathrm{n}$ of operating data is available for the model calibration:

$$
M D=\left[A_{1}, A_{2}, \ldots, A_{n}\right], \text { measured data } A_{1}, A_{2}, \ldots, A_{n}
$$

Where:

$$
\begin{aligned}
& \mathrm{A}_{\mathrm{n}}=\left[\mathrm{Q}_{\mathrm{An}}, \mathrm{P}_{\mathrm{An}}, \mathrm{N}_{\mathrm{An}}, \mathrm{W}_{\mathrm{An}}\right]^{\mathrm{T}} \\
& \mathrm{MI}=\left[\mathrm{P}_{\mathrm{B} 0}, \mathrm{~N}_{\mathrm{B} 0}\right] \\
& \mathrm{MO}=\left[\mathrm{Q}_{\mathrm{B} 0}, \mathrm{~W}_{\mathrm{B} 0}\right]
\end{aligned}
$$

The procedure to find the outputs (airflow rate $\mathrm{Q}_{\mathrm{B} 0}$ and fan power $\mathrm{W}_{\mathrm{B} 0}$ ) is described below.

The data are first generated from fan laws based on input fan static pressure $\mathrm{P}_{\mathrm{B} 0}$ Equation 12:

$$
\begin{aligned}
& \mathrm{Q}_{\mathrm{Bi}}=\mathrm{Q}_{\mathrm{B} 0}\left(\frac{\mathrm{P}_{\mathrm{B} 0}}{\mathrm{P}_{\mathrm{Bi}}}\right)^{0.5}, \mathrm{~W}_{\mathrm{Bi}}=\mathrm{W}_{\mathrm{B} 0}\left(\frac{\mathrm{P}_{\mathrm{B} 0}}{\mathrm{P}_{\mathrm{Bi}}}\right)^{1.5}, \\
& \mathrm{~N}_{\mathrm{Bi}}=\mathrm{N}_{\mathrm{B} 0}\left(\frac{\mathrm{P}_{\mathrm{B} 0}}{\mathrm{P}_{\mathrm{Bi}}}\right)^{0.5} \text { for } \mathrm{i}=1, \ldots \mathrm{n}
\end{aligned}
$$

Then, using linear interpolation, the model outputs are Equation 13 and 14:

$$
\mathrm{Q}_{\mathrm{B} 0}=\frac{\mathrm{N}_{\mathrm{Bi}+1}-\mathrm{N}_{\mathrm{B} 0}}{\mathrm{~N}_{\mathrm{Bi}+1}-\mathrm{N}_{\mathrm{Bi}}} \times \mathrm{Q}_{\mathrm{Bi}}+\frac{\mathrm{N}_{\mathrm{B} 0}-\mathrm{N}_{\mathrm{Bi}}}{\mathrm{N}_{\mathrm{Bi}+1}-\mathrm{N}_{\mathrm{Bi}}} \times \mathrm{Q}_{\mathrm{Bi}+1}
$$

where, $\mathrm{Q}_{\mathrm{Bi}}<\mathrm{Q}_{\mathrm{B} 0}<\mathrm{Q}_{\mathrm{Bi}+1}$.

$$
\mathrm{W}_{\mathrm{B} 0}=\frac{\mathrm{N}_{\mathrm{Bi}+1}-\mathrm{N}_{\mathrm{B} 0}}{\mathrm{~N}_{\mathrm{Bi}+1}-\mathrm{N}_{\mathrm{Bi}}} \times \mathrm{W}_{\mathrm{Bi}}+\frac{\mathrm{N}_{\mathrm{B} 0}-\mathrm{N}_{\mathrm{Bi}}}{\mathrm{N}_{\mathrm{Bi}+1} 0 \mathrm{~N}_{\mathrm{Bi}}} \times \mathrm{W}_{\mathrm{Bi}+1}
$$

where, $\mathrm{W}_{\mathrm{Bj}}<\mathrm{W}_{\mathrm{B} 0}<\mathrm{W}_{\mathrm{Bj}+1}$. 


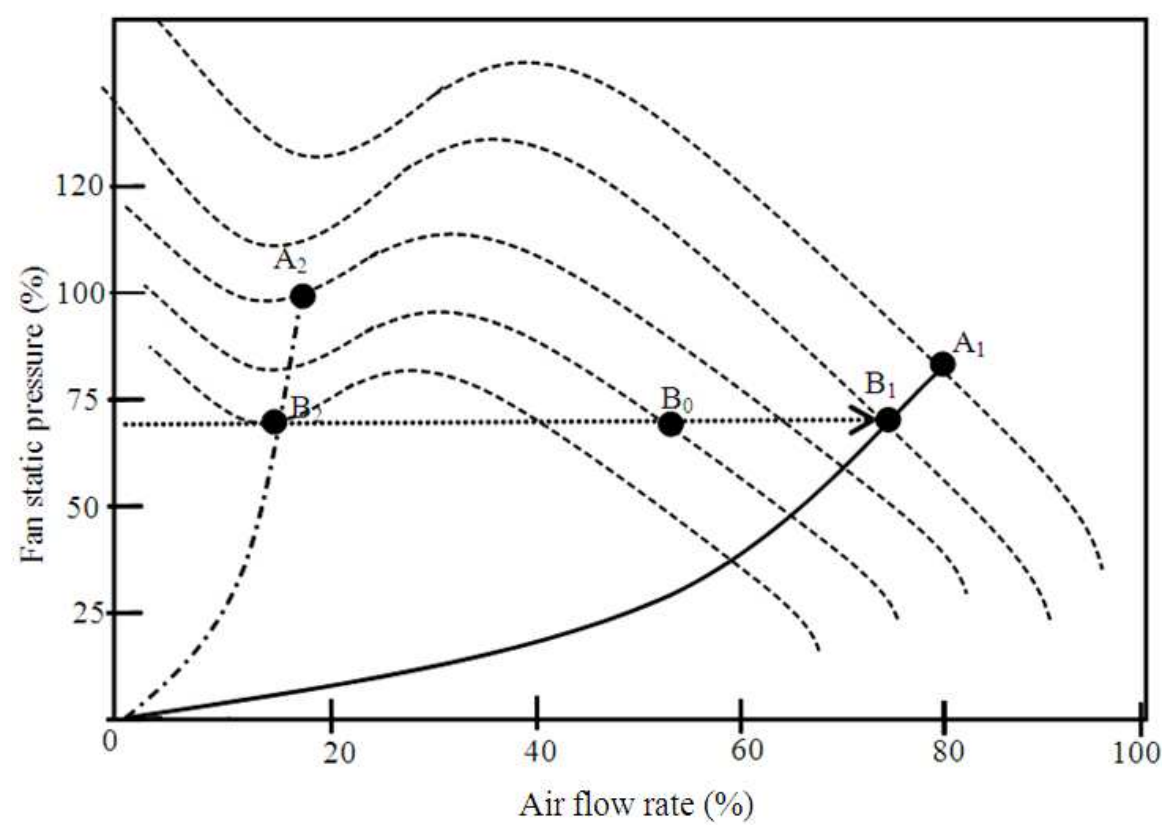

Fig. 1. Fan and system performance curves

\section{RESULTS}

The proposed model is first evaluated using a set of fan performance data obtained from two different manufacturers $\mathrm{A}$ and $\mathrm{B}$ for roof top unit packages with capacity ranging from 2 tons to 20 tons ( $7 \mathrm{~kW}$ to 70.2 $\mathrm{kW})$. Second, the model is validated against data collected from an existing system. The Simple Fan Model (SFM) and Detailed Fan Model (DFM) described above are also considered along with the proposed Fan Model (FM). The Coefficient of Variance (CV) is used as a statistical index for the model accuracy. In the evaluation process, different sizes of data required for the model calibration are considered with three cases of variable combinations:

\section{Case-I}

Inputs: Pressure and speed

Outputs: Airflow and power

\section{Case-II}

Inputs: Air flow rate and pressure

Outputs: Speed and power

\section{Case-III}

Inputs: Airflow rate and speed

Outputs: Pressure and power

\subsection{Model Evaluation Using Manufacturers' Data}

To evaluate the model using the manufacturers' data, first three data points $(n=3)$ with low, medium and high airflow rates for model calibration are selected from the available set of manufacturers' data (120 operating points). Then the model is validated against the remaining data $(120-3=117)$. Figure 2 and 3 show a comparison of the power and pressure obtained from manufacturer's data of a 15 ton $(52.7 \mathrm{~kW})$ package unit and simulated by FM, SFM and DFM. The straight line is a one-to-one line, indicating agreement between the actual and simulated data. As discussed before, the simple model is based on finding only the power as a function of airflow rate and the model does not respond to the variations of pressure at any given flow. As the manufacturer's data includes a set of power and pressure combinations at a given flow, the simple model produces always the same power and does not respond to the pressure variations. The SFM fails to follow the variation of the fan pressure at a given airflow rate and the model errors are very large (the coefficient of variance $\mathrm{CV}$ is around 50\%). The detailed model DFM can improve the results and the simulated power somewhat follows the pressure patterns. Similarly, the proposed fan model FM can further improve the results and the CV drops to 5.5\% when only three data points $(n=3)$ are used for calibration. 
However, the simple model needs four different operating points $(n=4)$ and the detailed model uses five points $(n=5)$ to find the polynomial coefficients. The accuracy of the proposed model depends on the size $\mathrm{n}$ of data used for calibration, for instance, by using four data points $n=4$ instead of three $n=3$, the $\mathrm{CV}$ will drop to $1.52 \%$. Figure 4 shows the variations of $\mathrm{CV}$ due to the size $\mathrm{n}$ for a 15 ton package unit (for airflow rate of Case-I and Manufacturer A). The accuracy increases significantly with a larger set of data $\mathrm{n}$ used for model calibration, as a small interval will be used for interpolation.

Table 1 and 2 show the CVs resulted by comparing the airflow rates obtained from two different manufacturers and simulated by the proposed model for various sizes of rooftop package units. The tables show the CV for case-I and only for the airflow rate outputs, whereas the results of other cases are summarized in Table 3. The average $\mathrm{CV}$ and the standard deviation STDs of the CVs are determined from the CVs' values obtained from various sizes of the package units ( 2 to 20 tons). It also includes the results from the detailed fan model calibrated by five operating points $n=5$. In caseI, the detailed fan model DFM simulates the airflow rate using the iteration technique. Initial value of air flow rate is assigned and then the calculation is repeated until convergence. The proposed model FM provides accurate results for the same size of data $n=5$. For the data of manufacturer $\mathrm{A}$, the average $\mathrm{CV}$ resulted by calculating the airflow rate (case-I) by the proposed model FM is $1.46 \%$, compared to the $\mathrm{CV}$ of $12.5 \%$ in the detailed model. The average $\mathrm{CV}$ when the power is simulated by FM is $3.49 \%$, compared to $9 \%$ for the detailed model.

\subsection{Model Evaluation Using Measured Data}

The proposed model is evaluated on an existing VAV system. The simulated results are compared with measured data collected from the existing VAV system under normal operations and covering three months (May, June and July). The data were collected at 5 min intervals. Different operating data were selected for the model calibration. For example, when the size of the data is $n=$ 5 , five different operation conditions with airflow rates of $100,85,75,60$ and $50 \%$ of design airflow rate are chosen. The design airflow rate is $25000 \mathrm{~L} / \mathrm{s}$ (53191 CFM). Figure 5 and 6 show the airflow rate and power comparisons for only five days. However, Table 4 shows the $\mathrm{CV}$ results for the three months. The proposed model FM provides very accurate results comparing to the simple and detailed models. For instance, the CV for airflow rate estimation drops from 11.2 to $3.12 \%$ by using the FM model instead the detailed model. Using the ten data points for model calibration, the CVs for the FM are within $1.37-1.89 \%$. These results indicated that the FM model can accurately simulate the airflow rate, pressure, speed, or power and the accuracy increases significantly by increasing the data size $\mathrm{n}$ for the model calibration.

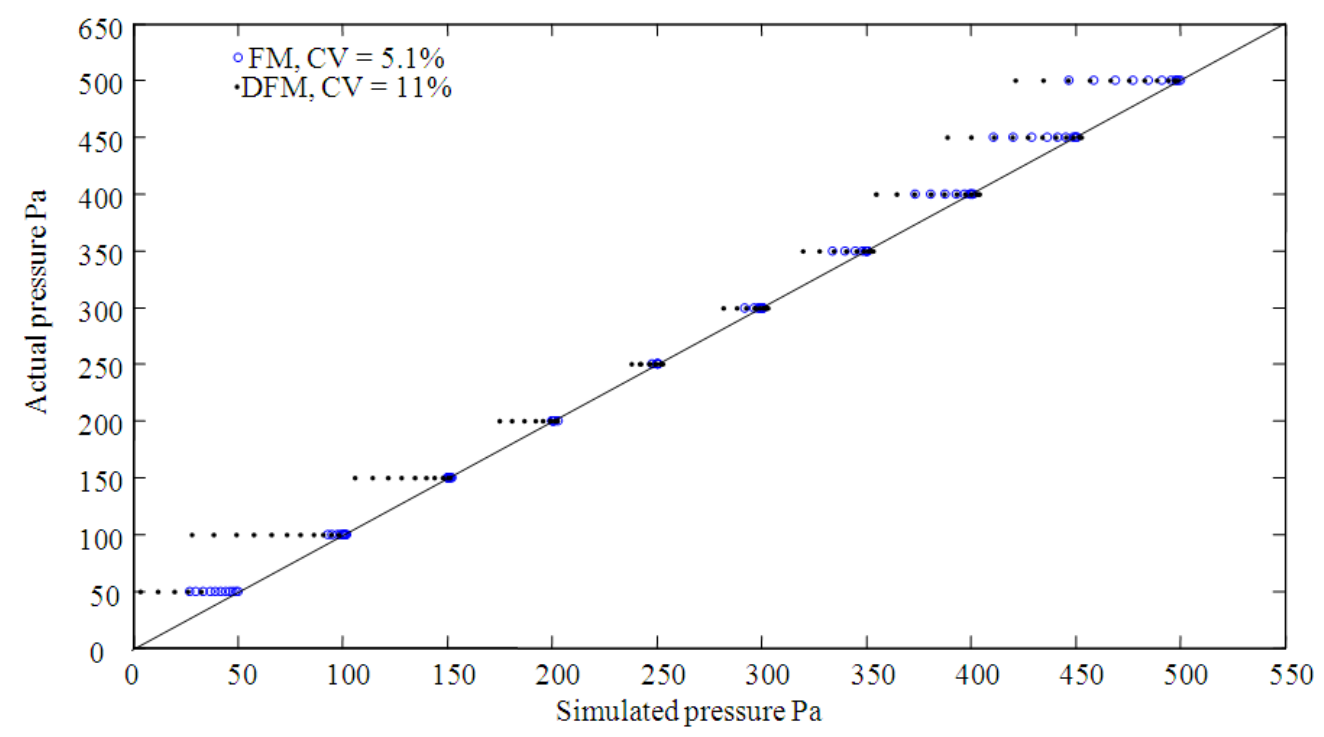

Fig. 2. A comparison of the pressure collected from the manufacturer's data of a 15 ton $(52.7 \mathrm{~kW})$ package unit and those simulated by the proposed model FM, simple model SFM and detailed model DFM 
Nabil Nassif et al. / American Journal of Engineering and Applied Sciences 7 (1): 36-44, 2014

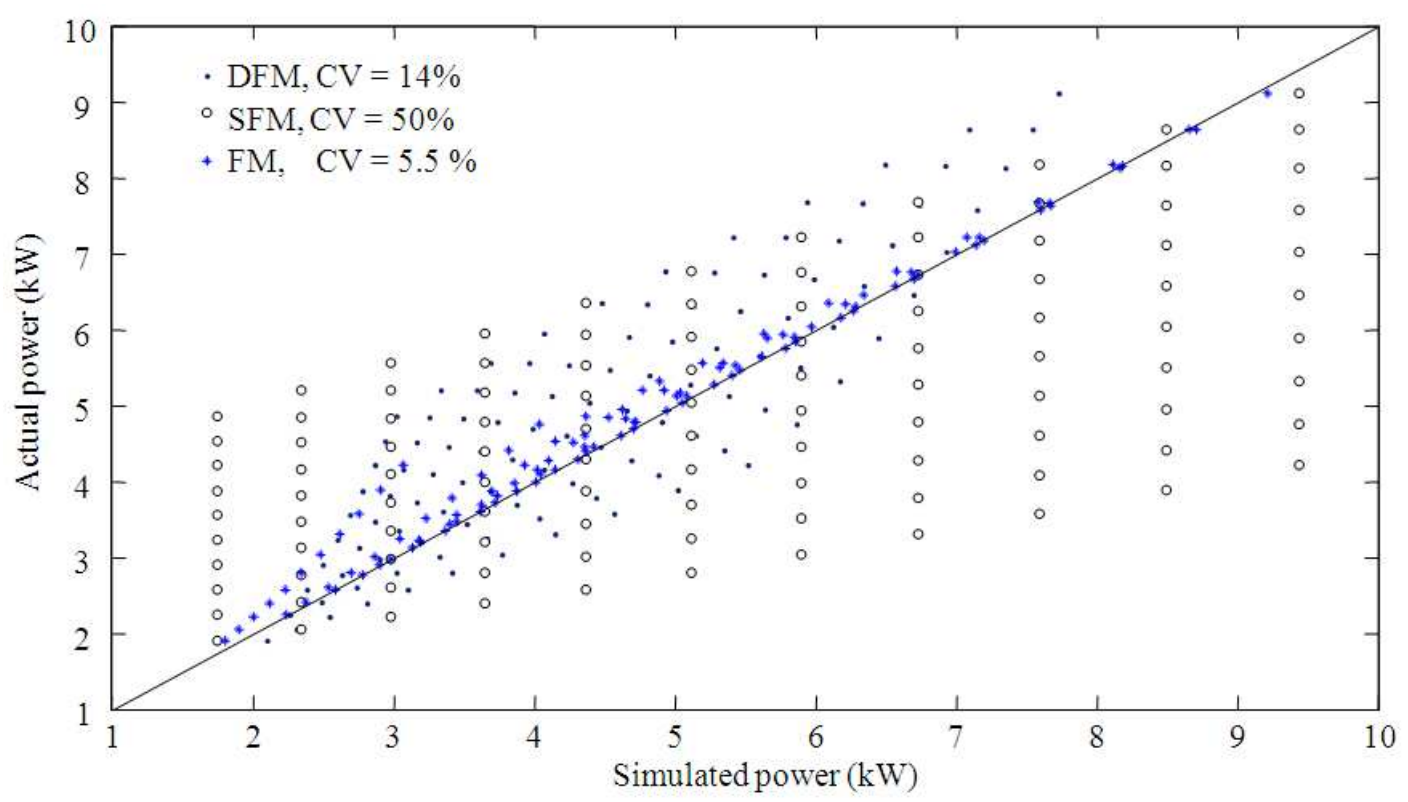

Fig. 3. A comparison of the power collected from the manufacturer's data of a 15 ton $(52.7 \mathrm{~kW})$ package unit and those simulated by the proposed model FM, simple model SFM and detailed model DFM

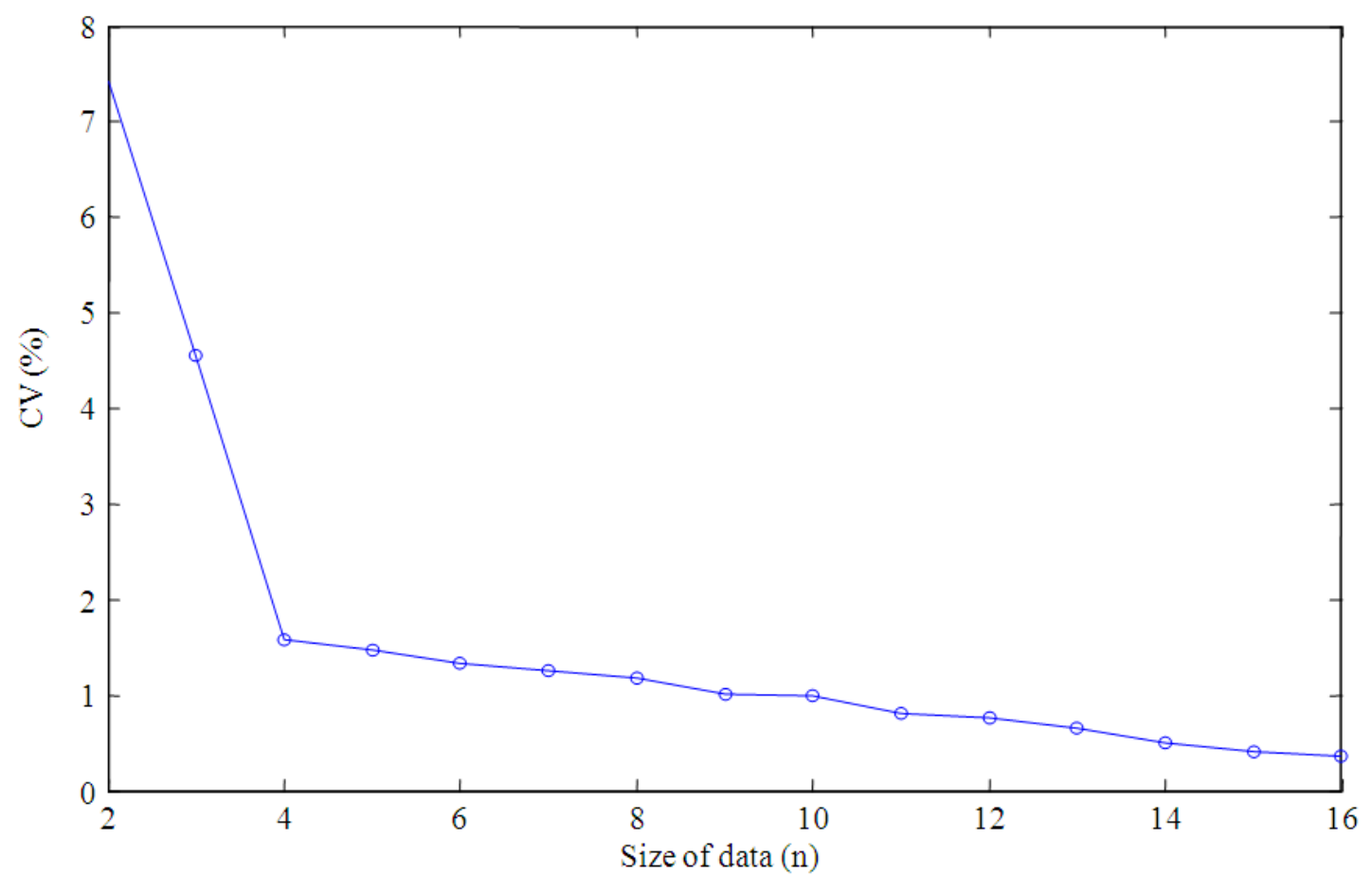

Fig. 4. The variations of $\mathrm{CV}$ resulted by the proposed model with the data size $\mathrm{n}$ used for model calibration and for the 15 ton (52.7 $\mathrm{kW}$ ) package unit (for airflow rate of Case-I and Manufacturer A) 
Nabil Nassif et al. / American Journal of Engineering and Applied Sciences 7 (1): 36-44, 2014

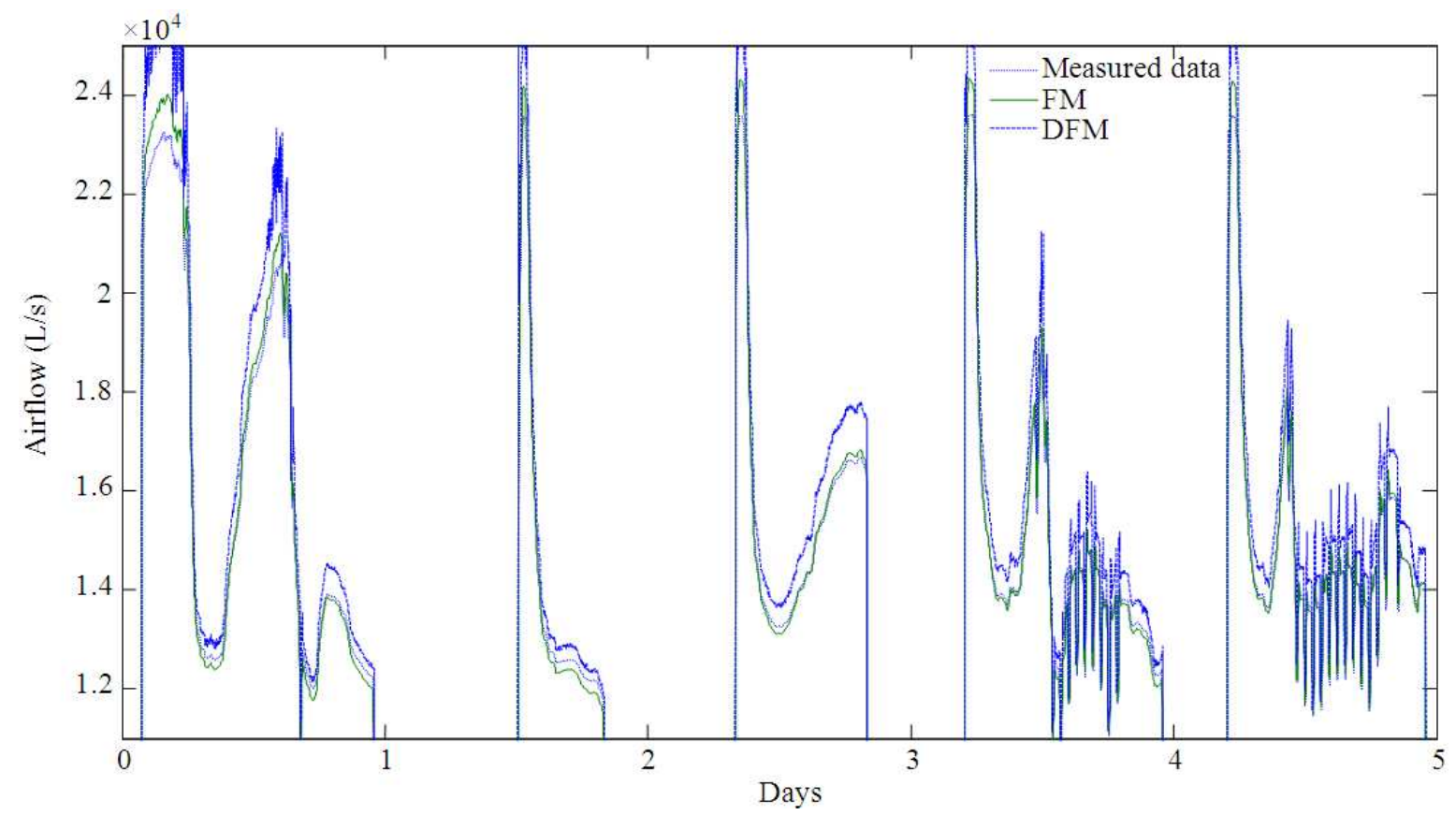

Fig. 5. A comparison of the air flow rates measured and simulated by proposed fan model FM and detailed model DFM for an existing system under normal operations (Five days in May)

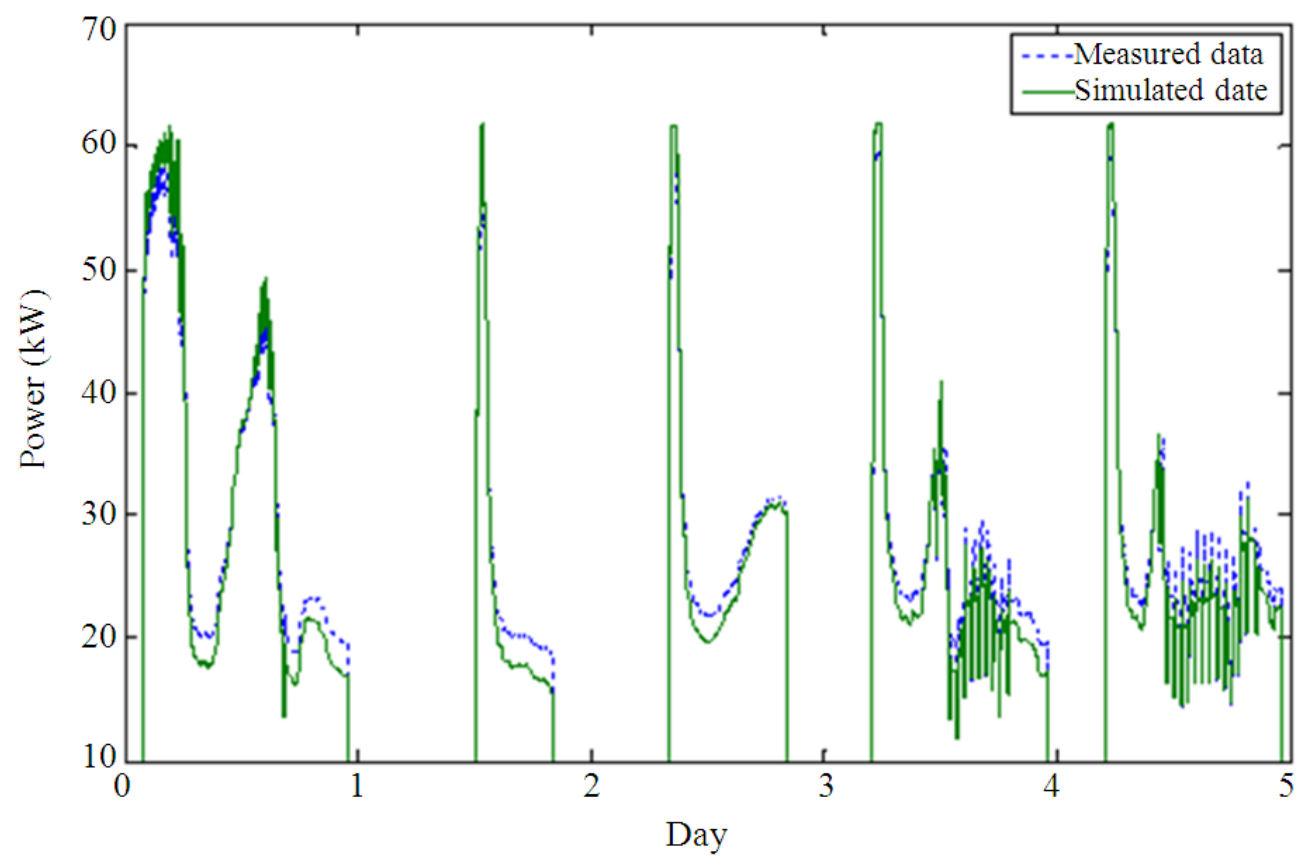

Fig. 6. A comparison of the fan power measured and simulated by proposed fan model FM and detailed model DFM for an existing system under normal operations (Five days in May) 
Nabil Nassif et al. / American Journal of Engineering and Applied Sciences 7 (1): 36-44, 2014

Table 1. CVs resulted by comparing the airflow rates obtained from the manufacturer (A) and simulated by the proposed model with different data sizes $\mathrm{n}$ used for the model calibrations (Case-I)

\begin{tabular}{lllll}
\hline & $\begin{array}{l}\text { Size } \mathrm{n}=2 \\
\text { manuf. A }\end{array}$ & $\begin{array}{l}\text { Size } \mathrm{n}=3 \\
\text { manuf. A }\end{array}$ & $\begin{array}{l}\text { Size } \mathrm{n}=5 \\
\text { manuf. A }\end{array}$ & $\begin{array}{l}\text { Size } \mathrm{n}=10 \\
\text { manuf. A }\end{array}$ \\
\hline 2 tons $(7 \mathrm{~kW})$ & 7.02 & 4.22 & 1.46 & 0.95 \\
3 tons $(10.5 \mathrm{~kW})$ & 8.34 & 5.67 & 1.12 & 0.98 \\
4 tons $(14 \mathrm{~kW})$ & 7.01 & 5.11 & 1.90 & 1.01 \\
5 tons $(17.6 \mathrm{~kW})$ & 6.55 & 4.99 & 1.22 & 0.97 \\
6tons $(21.1 \mathrm{~kW})$ & 6.77 & 4.89 & 1.38 & 1.14 \\
7.5 tons $(26.3 \mathrm{~kW})$ & 8.21 & 5.35 & 1.16 & 1.11 \\
8.5 tons $(29.8 \mathrm{~kW})$ & 7.89 & 4.87 & 1.67 & 1.15 \\
10 tons $(35.1 \mathrm{~kW})$ & 6.88 & 4.76 & 1.01 & 1.33 \\
12.5 tons $(43.9 \mathrm{~kW})$ & 7.55 & 5.37 & 1.51 & 0.94 \\
15 tons $(52.7 \mathrm{~kW})$ & 7.42 & 5.55 & 1.88 & 1.19 \\
17 tons $59.7 \mathrm{~kW})$ & 7.36 & 5.01 & 1.57 & 1.44 \\
18 tons $(63.2 \mathrm{~kW})$ & 6.87 & 4.66 & 1.31 & 1.03 \\
20 tons $(70.2 \mathrm{~kW})$ & 6.99 & 4.44 & 0.28 & 1.23 \\
Average & 7.30 & 4.99 & & 0.11 \\
Std & 0.54 & 0.41 & & \\
\hline
\end{tabular}

Table 2. CVs resulted by comparing the airflow rates obtained from the manufacturer (B) and simulated by the proposed model with different data sizes $\mathrm{n}$ used for the model calibrations (Case-I)

\begin{tabular}{lllll}
\hline & $\begin{array}{l}\text { Size } \mathrm{n}=2 \\
\text { manuf. B }\end{array}$ & $\begin{array}{l}\text { Size } \mathrm{n}=3 \\
\text { manuf. B }\end{array}$ & $\begin{array}{l}\text { Size } \mathrm{n}=5 \\
\text { manuf. B }\end{array}$ & $\begin{array}{l}\text { Size } \mathrm{n}=10 \\
\text { manuf. B }\end{array}$ \\
\hline 2 tons $(7 \mathrm{~kW})$ & 7.32 & 4.12 & 1.53 & 1.08 \\
3 tons $(10.5 \mathrm{~kW})$ & 9.78 & 4.89 & 1.11 & 1.11 \\
4 tons $(14 \mathrm{~kW})$ & 8.81 & 5.75 & 1.53 & 1.04 \\
5 tons $(17.6 \mathrm{~kW})$ & 7.89 & 5.11 & 1.88 & 1.03 \\
6 tons $(21.1 \mathrm{~kW})$ & 7.24 & 5.01 & 1.56 & 1.27 \\
7.5 tons $(26.3 \mathrm{~kW})$ & 6.89 & 5.43 & 1.88 & 1.26 \\
8.5 tons $(29.8 \mathrm{~kW})$ & 6.49 & 4.22 & 1.77 & 1.33 \\
10 tons $(35.1 \mathrm{~kW})$ & 7.81 & 5.76 & 1.04 & 1.49 \\
12.5 tons $(43.9 \mathrm{~kW})$ & 8.35 & 5.33 & 1.54 & 1.96 \\
15 tons $(52.7 \mathrm{~kW})$ & 8.32 & 5.66 & 1.12 & 1.54 \\
17 tons $59.7 \mathrm{~kW})$ & 6.89 & 5.23 & 1.07 & 1.36 \\
18 tons $(63.2 \mathrm{~kW})$ & 7.17 & 4.75 & 1.55 & 1.47 \\
20 tons $(70.2 \mathrm{~kW})$ & 6.56 & 4.56 & 0.28 & 1.44 \\
Average & 7.99 & 5.06 & & 0.18 \\
Std & 0.92 & 0.52 & & \\
\hline
\end{tabular}

Table 3. A summary of CV results for various model outputs (Case-I, Case-II and Case-III)

\begin{tabular}{|c|c|c|c|c|c|c|c|c|c|c|c|c|}
\hline \multirow{2}{*}{\multicolumn{2}{|c|}{ Manufacturers }} & \multirow[b]{3}{*}{ Indexes } & \multicolumn{8}{|c|}{ Proposed fan model } & \multirow{2}{*}{\multicolumn{2}{|c|}{$\begin{array}{l}\text { Detailed } \\
\text { fan model } \\
\text { Size } n=4\end{array}$}} \\
\hline & & & \multicolumn{2}{|c|}{ Size $n=2$} & \multicolumn{2}{|c|}{ Size $n=3$} & \multicolumn{2}{|c|}{ Size $n=5$} & \multicolumn{2}{|c|}{ Size $n=10$} & & \\
\hline Cases & Outputs & & $\mathrm{A}$ & $\mathrm{B}$ & $\mathrm{A}$ & $\mathrm{B}$ & $\mathrm{A}$ & $\mathrm{B}$ & $\mathrm{A}$ & $\mathrm{B}$ & $\mathrm{A}$ & $\mathrm{B}$ \\
\hline \multirow[t]{4}{*}{ Case-I } & \multirow[t]{2}{*}{ Airflow } & Average (CV) & 7.30 & 7.99 & 4.99 & 5.06 & 1.46 & 1.47 & 1.11 & 1.23 & 12.50 & 13.50 \\
\hline & & STD (CV) & 0.54 & 0.92 & 0.41 & 0.52 & 0.28 & 0.28 & 0.15 & 0.18 & 0.98 & 1.08 \\
\hline & \multirow[t]{2}{*}{ Power } & Average (CV) & 7.28 & 7.10 & 5.71 & 5.94 & 3.49 & 3.32 & 1.44 & 1.82 & 9.02 & 13.46 \\
\hline & & STD (CV) & 0.71 & 0.60 & 0.57 & 0.52 & 0.33 & 0.34 & 0.15 & 0.16 & 1.33 & 0.99 \\
\hline \multirow[t]{4}{*}{ Case-II } & \multirow[t]{2}{*}{ Airflow } & Average (CV) & 7.29 & 7.43 & 5.90 & 5.03 & 3.49 & 3.50 & 1.13 & 1.65 & 10.60 & 13.86 \\
\hline & & STD (CV) & 0.61 & 0.78 & 0.60 & 0.54 & 0.40 & 0.37 & 0.09 & 0.13 & 1.20 & 1.26 \\
\hline & \multirow[t]{2}{*}{ Power } & Average (CV) & 7.42 & 6.65 & 5.48 & 5.31 & 3.88 & 3.40 & 1.61 & 1.10 & 12.75 & 11.05 \\
\hline & & STD (CV) & 0.64 & 0.69 & 0.52 & 0.54 & 0.30 & 0.35 & 0.14 & 0.12 & 1.50 & 1.40 \\
\hline \multirow[t]{4}{*}{ Case-III } & \multirow[t]{2}{*}{ Airflow } & Average (CV) & 6.37 & 7.62 & 5.59 & 5.62 & 3.42 & 3.32 & 1.22 & 0.98 & 13.16 & 13.61 \\
\hline & & STD (CV) & 0.77 & 0.70 & 0.60 & 0.53 & 0.40 & 0.32 & 0.08 & 0.14 & 1.27 & 1.25 \\
\hline & \multirow[t]{2}{*}{ Power } & Average (CV) & 7.91 & 6.09 & 5.08 & 5.99 & 3.73 & 3.24 & 1.99 & 1.59 & 10.65 & 12.50 \\
\hline & & STD (CV) & 0.72 & 0.78 & 0.56 & 0.55 & 0.33 & 0.37 & 0.14 & 0.11 & 1.12 & 1.17 \\
\hline
\end{tabular}


Nabil Nassif et al. / American Journal of Engineering and Applied Sciences 7 (1): 36-44, 2014

Table 4. CVs obtained by comparing the simulated results and actual data for a period of three months

\begin{tabular}{|c|c|c|c|c|c|c|c|}
\hline \multicolumn{6}{|c|}{ Proposed model } & \multirow{2}{*}{$\begin{array}{l}\text { DFM } \\
\text { Size } n=5\end{array}$} & \multirow{2}{*}{$\begin{array}{l}\text { SFM } \\
\text { Size } n=4\end{array}$} \\
\hline Cases & Outputs & Size $n=2$ & Size $n=2$ & Size $n=5$ & Size $n=10$ & & \\
\hline \multirow[t]{2}{*}{ Case-I } & Airflow & 9.12 & 5.42 & 3.12 & 1.71 & 11.20 & - \\
\hline & Power & 8.56 & 6.11 & 3.32 & 1.78 & 12.30 & - \\
\hline \multirow[t]{2}{*}{ Case-II } & Speed & 10.31 & 6.81 & 3.87 & 1.89 & 10.86 & - \\
\hline & Power & 9.44 & 7.21 & 3.93 & 1.22 & 10.54 & 16.54 \\
\hline \multirow[t]{2}{*}{ Case-III } & Pressure & 8.45 & 4.89 & 3.05 & 1.46 & 9.59 & - \\
\hline & Power & 9.02 & 6.12 & 3.75 & 1.37 & 10.54 & 17.21 \\
\hline
\end{tabular}

\section{CONCLUSION}

The fan model proposed in this study uses a numerical analysis based on the interpolation technique for the data generated by basic fan laws. The model was tested for accuracy using data obtained from two different manufacturers and an actual VAV system. The results indicated that the model can accurately simulate the airflow rate, pressure, speed, or power and the accuracy in term of the coefficient of variance $\mathrm{CV}$ is less than $2 \%$. The model is able to use any two variables among all four variables of airflow rate, total fan pressure, speed and power as inputs or outputs. Any size of data can be used for the model calibration, obtained either from manufacturers or field measured data. However, the accuracy increases significantly through increasing the data size $n$ for the model calibration. The fan model can be used for several applications such as optimization, fault detection, modern airflow station technique and any commercial building models.

\section{REFERENCES}

Brandemuehl, M.J., S. Gabel and I. Andersen. 1993. A toolkit for secondary HVAC system energy calculation. American Society of Heating, Refrigerating and Air-Conditioning Engineers ASHRAE, Inc.
Clark, D.R., 1985. HVACSIM+ building systems and equipment simulation program: Reference manual. NBSIR 84-2996, U.S. Department of Commerce, Washington D.C.

DOE, 1980. DOE 2 reference manual, Part 1, Version 2.1. Lawrence Berkeley National, Department of Energy.

Dieckmann, J., K. McKenney and J. Brodrick. 2010. Variable frequency drives, Part 2: VFDs for blowers. ASHRAE J., 52: 58-62.

EERE, 2010. 2009 Buildings energy data book. U.S. Department of Energy, Energy Efficiency and Renewable Energy.

Joo, I.S. M. Liu and G. Liu, 2007. Application of fan airflow stations in air-handling units. Energy Eng., 104: 66-80. DOI: 10.1080/01998590709509494

Nassif, N., S. Moujaes and M. Zaheeruddin, 2008. Selftuning dynamic models of HVAC system components. Energy Build., 40: 1709-1720. DOI: 10.1016/j.enbuild.2008.02.026

Nassif, N., 2008. Performance analysis of supply and return fans for HVAC systems under different operating strategies of economizer dampers. Energy Build., 42: 1026-1037. DOI: 10.1016/j.enbuild.2010.01.015

Stein, J. and M. Hydeman, 2004. Development and testing of the characteristic curve fan model. ASHRAE Trans., 110: 347-356. 